\section{Conferência de direitos ou plano decenal?}

Lecture on rights or decennial plan?

\section{Aurea Satomi Fuziwara ${ }^{\star}$}

Introdução

O presente informe tem o objetivo de problematizar a $8^{\text {a }}$ Conferência Nacional dos Direitos da Criança e do Adolescente (que chamaremos aqui Conferência DCA), realizada de 7 a 10 de dezembro de 2009 com o tema "Construindo Diretrizes da Política Nacional dos Direitos da Criança e do Adolescente e do Plano Decenal". No número 93 desta mesma revista problematizamos questões conceituais sobre a conferência e não nos ateremos a este aspecto, aprofundando outros elementos que nos parecem complementares e conjunturalmente relevantes. Para as reflexões ora apresentadas consideramos a trajetória das conferências municipais e estadual de São Paulo e o resultado da nacional, por meio de acompanhamento enquanto membro da Comissão Organizadora ${ }^{1}$ e contato com participantes.

* Assistente social, funcionária do TJ/SP licenciada, presidente do Cress $9^{a}$ Região-São Paulo/SP — Brasil, na gestão 2008-11, militante e pesquisadora do FEDDCA-SP, docente de graduação e pósgraduação.E-mail: aureafuziwara@yahoo.com.br.

1. O Conselho Estadual de Direitos da Criança e do Adolescente de São Paulo convidou o FEDDCA-
Participaram na $8^{\mathrm{a}}$ Conferência DCA 1.800 delegados, sendo que seiscentos eram adolescentes. O Conanda publicou em dezembro de 2008 o texto-base para orientar os municípios e estados, mas esse documento trazia, simultaeamente a referências sobre o conteúdo a ser tratado em forma de eixos, e aspectos operacionais, como cronogramas, gerando dificuldades de entendimento, o que foi alvo de críticas por parte dos municípios e estados.

Os municípios com conselhos de direitos e sociedade civil mais organizados buscaram alternativas para superar estes entraves, construindo procedimentos particulares, que, por sua vez, acarretam dificuldades na consolidação do relatório regional ou estadual.

\section{Conferência ou plano decenal?}

$\mathrm{O}$ aspecto negativo mais ressaltado por grupos críticos à $8^{\mathrm{a}}$ Conferência Nacional DCA foi o fato de não ter havido efetiva avaliação das políticas voltadas para a infância, que foram ou deveriam ter sido efetivadas pelos municípios, estados e o próprio governo federal, bem como os processos e resultados, ao longo dos últimos dois anos. O objetivo da Conferência foi "analisar, definir e deliberar as diretrizes da Política Nacional dos Direitos da

-SP para compor a Comissão Organizadora, o que foi aceito com vistas a acompanhar, contribuir e fiscalizar este processo. É público que o FEDDCA-SP é crítico histórico da atuação do Condeca-SP. 
Criança e do Adolescente, com vista à elaboração do Plano Decenal da Política dos Direitos da Criança e do Adolescente". Diante disso, a centralidade da Conferência, que é conferir e avaliar, para então propor, ficou prejudicada. Em todas as fases houve muito conflito de entendimento: enquanto a população tentava falar de sua realidade, das ausências do Estado, das demandas por direitos, a conferência voltava-se para a aprovação das diretrizes conforme, os cinco eixos delimitados pelo Conanda:

- promoção e universalização de direitos em um contexto de desigualdades;

- proteção e defesa no enfrentamento das violações de direitos humanos de crianças e adolescentes;

- fortalecimento do sistema de garantia de direitos;

- participação de crianças e adolescentes em espaços de construção da cidadania;

- gestão da política.

Ao analisarmos os processos e resultado das conferências, verificamos a insuficiência dos debates e da legitimação das demandas populares. Em muitos relatórios estaduais podemos observar a ausência de diretrizes, deixando hipóteses de que as orientações básicas do Conanda não foram compreendidas ou foram rejeitadas. Embora os relatórios expressem o acatamento das orientações, o conteúdo dos resultados evidencia que não há compreensão adequada do que sejam diretrizes. Este pro- cesso que poderia trazer um bom debate sobre o papel das conferências acabou tensionado pelo receio de municípios e estados não terem seus delegados aceitos na instância nacional, como no caso de São Paulo.

Segundo Tatiane Cardoso, ${ }^{2}$ delegada de São Paulo pelo segmento Fórum Estadual dos Direitos da Criança e do Adolescente, "a política posta não foi conferida de fato, para estabelecermos as prioridades e sabermos quais os pontos fundamentais dos quais devemos estrategicamente partir".

$\mathrm{O}$ dr. Paulo Garrido de Paula reafirmou, em sua palestra, que os conselhos de direitos são órgãos deliberativos e têm o dever de deliberar sobre política direcionada à criança e ao adolescente. A decisão política deve ser adequada, e para isto devem ser respeitadas as especificidades de cada local. Enfatizou que ter direito significa ter interesses juridicamente protegidos, ou seja, trata-se de uma necessidade que o Estado resolveu proteger. Indaga o ilustre jurista: "Mas por que eles não se realizam? Por duas razões: pela negativa de sua existência, negada não na retórica, mas no cotidiano e também pela negativa de sua eficácia”. Vale salientar que nessa Conferência não foi debatida a inconstitucionalidade das "doações casadas" aos fundos municipais, tão em prática no país sem o pronunciamento de conselhos e do Ministério Público. Em tal

2. Advogada atuante no Cedeca em São Paulo, militante do FEDDCA-SP, que contribui para este artigo. 
situação, os conselhos de direito são aviltados em seu poder deliberativo, e as pessoas jurídicas condicionam onde o recurso público será destinado (em geral em áreas de seu próprio interesse).

Neste sentido, a questão central que temos alertado ao debater criticamente as conferências é quanto à distorção de seu caráter participativo e de controle social (da sociedade sobre o Estado), tendo por efeito negar a importância e a necessidade da participação popular nos rumos da própria sociedade.

\section{Cidade dos Direitos da Criança e do Adolescente}

Foi construída com 6 mil metros para receber até 8 mil crianças e adolescentes durante a $8^{\mathrm{a}}$. Conferência DCA, com espaços para interação, apresentando as instituições responsáveis pela promoção e defesa dos direitos de crianças e adolescentes, pretendendo que os visitantes conhecessem os papéis e o funcionamento do Conselho Tutelar e de Direitos, do Ministério Público, da Delegacia e da Vara Especializada da Infância e da Juventude, da Prefeitura e da Defensoria Pública.

\section{A participação dos adolescentes}

Houve grande presença de adolescentes, mas o processo desencadeado ainda é insuficiente e inadequado. No estado de São Paulo, é importante salientar, desde
1999 o Fórum Estadual de Defesa dos Direitos da Criança e do Adolescente (FEDDCA-SP) vem construindo a proposta da conferência lúdica, no qual o intuito é que não apenas sejam aplicadas metodologias para garantir a participação dos meninos e meninas, mas que eles sejam efetivamente ouvidos e considerados, legitimando suas avaliações e proposituras. Nos anos seguintes, realizamos duas conferências lúdicas estaduais independentes, no qual adolescentes participaram de oficinas e nessas foram sendo identificadas as lideranças que conduziriam todo o processo: organização e condução das atividades. A divulgação e a mobilização ficaram por conta dos adultos, mas sob o comando dos jovens líderes. No estado de São Paulo, o Condeca-SP passou a assumir as conferências lúdicas, mas alterando a metodologia do FEDDCA-SP. Pudemos, contudo, garantir que nesse ano duas de suas diretrizes priorizadas pelos adolescentes fossem automaticamente acolhidas no relatório estadual. Cabe aos conselhos criar as resoluções para efetivar as deliberações das conferências. Contudo, o que tem ocorrido atualmente na maioria de municípios e estados são miniatividades, mas sem valorizar a capacidade expressiva e a particularidade da construção de ideias de crianças e adolescentes. A maioria das atividades oferece materiais pedagógicos e os adultos continuam conduzindo todo o processo.

Afirmamos que o lúdico compõe a construção do sujeito social, mas atualmente temos outros processos de sociabilidade marcada pelo capital: competitividade, mecanicidade e ausência de relações 
fraternas em que todos sejam vistos em sua importância. É preocupante que não se tome o devido cuidado para que os adolescentes não sejam preparados para cometer os mesmos erros e condutas questionáveis dos adultos que atuam nas conferências.

Conforme o dr. Paulo Garrido de Paula, a política de atendimento dos direitos da criança e do adolescente prevista no ECA (art. 86) é explicitada por meio de linhas de ação (art. 87) e de diretrizes (art. 88), que trazem as indicações de percurso, as instruções para o combate aos desvios e procedimentos de organização.

Quando o Conanda definiu que a sociedade civil estaria representada pelas entidades com assento nos conselhos e reduzindo as vagas para os fóruns estaduais DCAs, afetou a construção histórica e a luta em defesa de que a conferência é espaço da população, nos termos constitucionais. Houve conferência em que garantimos $70 \%$ de sociedade civil. ${ }^{3}$ Wanderlino Nogueira Neto, renomado defensor de direitos humanos da criança e do adolescente, alerta que a sociedade civil não se restringe às entidades (sejam ONG ou Oscip), havendo um sério problema a ser enfrentado. O ECA, salientemos, trata de "organizações representativas", sendo flagrante o erro reiterado em todos os espaços, inclusive na composição do Conanda.

3. Vale anotar que os movimentos sociais estão tão desarticulados que nem mesmo as boas conquistas nas diferentes áreas são compartilhadas, e vemos que cada área faz conferências muito diferentes entre si, em especial na composição dos delegados.
Mocõees: saldo político da conferência

As moções são utilizadas de formas bastante interessantes. Conforme o regimento, deveriam ter a aprovação de $10 \%$ dos participantes. Observamos que em geral tratam de assuntos que não puderam ser contemplados nas deliberações, trazendo conteúdos tanto estruturais quanto conjunturais. Por se tratar de uma conferência que aprovou pretensas diretrizes, observa-se que as 21 moções aprovadas tiveram, em sua maioria, caráter político, o que é positivo. Dentre as moções, podemos destacar a ênfase contra o agravamento da violência, sendo que foi repudiado o Projeto de Lei n. 5.524/2009 proposto pelo deputado federal Márcio Franca (PSB), para que os conselheiros tutelares tenham direito a porte de arma de fogo. Outras moções importantes referem-se às concepções: houve novamente repúdio à implantação da metodologia de depoimento sem dano sem o devido debate com a sociedade e a favor da regulamentação da propaganda de alimentos voltados para a criança, respectivamente moções 21 e 4 .

A moção 8, muito polêmica, exige a “alteração do art. $166, \S 5^{\circ}$, da Lei de Adoção n. 12.010/09, ${ }^{4}$ que prevê a possibilidade de retratação, até a publicação da sentença, dos genitores que entregarem o filho para adoção, na Vara da Infância e Juventude, em audiência. Este dispositivo

4. A "nova Lei da Adoção" é ainda muito debatida e questionada, por ter resgatado questões já superadas na concepção do ECA e outras legislações. 
privilegia os pais em detrimento das crianças e adolescentes". Outras foram bastante consensuais: a moção 1 , contrária às propostas de redução da maioridade penal; e a moção 5, de "repúdio às decisões judiciais que restringem ou violam o direito constitucional das crianças e dos adolescentes de ir e vir, a exemplo do toque de recolher".

Sobre o orçamento, a moção 14 aprova a "recomendação" ao Conanda, à Frente Parlamentar pelos Direitos da Criança e do Adolescente e demais atores do SGDCA para fazer gestões políticas junto ao Congresso Nacional e aos governos federal e estaduais para apoio à Emenda Aditiva de Plenário ao Projeto de Lei n. 5.938, de 2009, para destinação de $1 \%$ dos royalties do Pré-Sal aos fundos nacional, estaduais e municipais dos direitos das crianças e adolescentes. A dra. Irene Rizzini afirmou esta questão em sua palestra, salientando que não tem como efetivar a política sem conectá-la diretamente ao orçamento".

\section{Diretrizes}

Houve polêmica em torno da criação de "secretarias nacionais, estaduais e municipais dos direitos das crianças e dos adolescentes", o que não foi aceito, mas aprovado em forma de moção, defendida em especial pelo grupo de adolescentes.

Uma das diretrizes mais relevantes exige a garantia da prioridade absoluta para a criança e o adolescente no ciclo orçamentário, tanto no Plano Plurianual, na Lei de Diretrizes Orçamentárias e na Lei Orçamentária Anual, o que implicitamente exige que o próprio calendário das Conferências tenha o intuito de incidir sobre tais orçamentos (devendo ser planejado para anteceder o debate e ser determinante na aprovação de tais orçamentos).

Há ênfase em diretrizes que visam a articulação de ações, que possivelmente levará à consolidação no Plano Decenal das principais diretrizes já existentes em outros planos temáticos. ${ }^{5}$ Retoma-se a relevância do Sistema Único de Assistência Social, Suas, da saúde, via SUS e da educação para a cidadania, garantindo-se período integral com atividades programadas junto com outras políticas sociais (esporte, lazer, cultura, saúde etc.). Há ênfase na questão da gestão, monitoramento e avaliação de forma permanente, com participação da criança e do adolescente. Assim, abordou-se a necessidade de que sejam criados indicadores, análises situacionais e gerenciais, contemplando as diversas realidades culturais e regionais. Novamente há grande preocupação com

5. O FEDDCA-SP já vinha tensionando há muito que a ausência de uma política efetiva, a partir do ECA, é a questão central para este debate. Em 2008, quando o Comissariado da ONU que visitou o Brasil para aferir a implementação da Convenção Internacional dos Direitos da Criança e do Adolescente, estivemos na mesa final com a representante Rosa Maria Ortiz, que confirmou nossa posição, alertando que o Brasil não tinha um órgão central que estivesse articulando essas ações. Sabemos que a Secretaria Especial de Direitos Humanos tem esta função executiva, mas efetivamente não está a cumprindo de modo articulado. 
estudos, pesquisas e qualificação dos profissionais, exigindo-se inclusive seleção pública, construção de carreiras e valorização dos trabalhadores. É importante observar aqui o valor da sistematização das experiências e pesquisas relacionadas ao trabalho profissional, às metodologias e aos direitos trabalhistas, posto que todas estas matérias afetam diretamente a efetivação dos direitos.

Ao mesmo tempo em que duas propostas tratam da necessidade de política de atendimento e apoio à família, inclusive garantindo-se os princípios traçados no ECA e no Plano de Convivência Familiar e Comunitária, não se aborda a participação da família na gestão da política. Portanto, há evidência de que o tema participação aparece nesta $8^{\mathrm{a}}$ Conferência muito mais como resposta à provocação (era um dos eixos), mas focando crianças e adolescentes. Falou-se das diversas instituições, conselhos, mas não há uma diretriz que trate do efetivo direito da família em ser protegida em seus direitos, princípio para proteção integral das crianças e adolescentes, independentemente do tipo de laço que a legitima enquanto família.

\section{Os próximos passos}

A partir das propostas de diretrizes aprovadas na Nacional, o grupo de trabalho, que envolve nove ministérios e consultores do Conanda, fará, em julho de 2010, a entrega do documento para o presidente Lula e outros candidatos a cargos políticos, com o objetivo de que eles assinem um termo de compromisso. Pretende-se que essa entrega seja precedida de um encontro com os conselhos estaduais e municipais e também de uma consulta pública, para que possam ser agregadas mais sugestões. A crítica que o movimento de defesa dos direitos da criança e do adolescente tem feito é que a consulta pública é um aparente instrumento democrático, pois no resultado final são incluídas questões aprovadas pelos representantes dos ministérios e consultores, portanto, pela vontade governamental. Será fundamental que sejam garantidas não apenas as deliberações dessa Conferência, mas de todas as que as antecederam, ainda que atualmente tentem afirmar que apenas a $7^{\mathrm{a}}$ e a $8^{\mathrm{a}}$ foram deliberativas.

A luta do movimento de defesa dos direitos da criança e do adolescente não é apenas por um segmento geracional, mas para afirmar que é com a construção da democracia real, da participação, do confronto de ideias, do enfrentamento de diferenças e respeito à diversidade que poderemos nos construir como sujeitos capazes de alterar os rumos da sociedade. Reiterando práticas que impedem esse exercício tão novo e, por isso mesmo, tão necessitado de radicalidade (indo às causas, às raízes dos problemas), não avançaremos.

Embora tenha sido nauseantemente visível a busca dos adultos em manipular os adolescentes, a grande maioria deles não se deixou influenciar por tais atitudes. Garantir a participação dos adolescentes é uma conquista da luta do movimento 
social, pois acreditamos e apostamos na juventude. Acreditamos que somente a democracia real poderá auxiliar na ruptura dos rumos de um país que, apesar de ser extremamente rico, possui gravíssima desigualdade social e injustiça.

Os próximos passos não precisam aguardar ordem oficial: o conteúdo de todas as conferências devem ser resgatadas, alimentando a construção do Plano Decenal, mas possibilitando construir uma política para o país que efetive a proteção integral à criança e ao adolescente. Não consolidar em ações concretas é afirmar aos participantes, em especial aos adolescentes, que o controle e a participação social são meras expressões de linguagem. Aos municípios, além da tarefa de manter o debate, caberá consolidar as deliberações em resoluções dos seus conselhos de direitos e de políticas setoriais. É necessário que as deliberações se materializem formalmente e que se traduzam em política de Estado (e não meros programas de governos). Assim, poderemos afirmar que a democracia é possível e que está sendo construída.

Artigo recebido em dez./2009

Aprovado em jan./2010 